\title{
Vitamin D assessment in perioperative medicine and critical care
}

\section{A prospective observational pilot study}

\author{
Paul Zajic (D) - Stefan Heschl · Michael Schörghuber · Petra Srekl-Filzmaier · Tatjana Stojakovic · Viktoria Weixler • \\ Sieglinde Zelzer · Karin Amrein
}

Received: 29 July 2019 / Accepted: 15 November 2019 / Published online: 4 December 2019

(C) The Author(s) 2019

\begin{abstract}
Summary
Background There is controversy about the impact of acute illness on vitamin D levels. This study was carried out to assess the influence of perioperative fluid loading on 25-hydroxy-vitamin D [25(OH)D] levels. The study evaluated the clinical utility of a commonly available chemiluminescence assay (ECLIA, IDS-iSYS) and liquid chromatography/mass spectrometry (LCMS/MS) in the diagnosis of vitamin D deficiency in this setting.

Methods In this prospective observational pilot study in adult patients undergoing cardiovascular surgery on cardiopulmonary bypass (CPB), blood samples drawn at preoperative baseline (t1), after weaning from CPB (t2), on intensive care unit (ICU) admission
\end{abstract}

(t3) and on the first (t4) and second (t5) postoperative days were analyzed.

Results A total of 26 patients (130 samples) were included in this study. Fluid loading by CPB led to a median reduction of $25(\mathrm{OH}) \mathrm{D}$ by $-22.6 \%$ (range $-54.5 \%$ to $-19.5 \%$ ) between $t 1$ and $t 2$. Cohen's kappa ( $\kappa)$ for method agreement for vitamin $\mathrm{D}$ deficiency (tested cut-off values $20 \mathrm{ng} / \mathrm{ml}$ and $12 \mathrm{ng} / \mathrm{ml}$ ), was $\kappa=0.291$ $(p<0.001)$ and $\kappa=0.469(p<0.001)$, respectively. The mean difference between measurements by ECLIA and LC-MS/MS was $4.8 \mathrm{ng} / \mathrm{ml}( \pm 5.7)$, Pearson's $\mathrm{r}$ for correlation was $0.73(p<0.001)$. The biologically inactive C3-epimer did not contribute to $25(\mathrm{OH}) \mathrm{D}$ levels assessed by LC-MS/MS.

\footnotetext{
Author contributions $\mathrm{PZ}$ and KA designed the study, $\mathrm{SH}$, PSF, MS, VW and PZ performed patient screening, information and inclusion, SZ performed laboratory measurements, $\mathrm{PZ}$ and KA performed the statistical analyses, PZ wrote the manuscript, PZ, SH, MS, PSF, TS, VW and KA critically revised the manuscript for important intellectual content. All authors approved of the manuscript ahead of submission.

\section{P. Zajic, MD (ه)}

Div. of General Anaesthesiology, Emergency- and Intensive Care Medicine, Dept. of Anaesthesiology and Intensive Care Medicine, Medical University of Graz, Graz, Austria paul.zajic@medunigraz.at

S. Heschl, MD PhD · M. Schörghuber, MD

Div. of Anaesthesiology for Cardiovascular and Thoracic

Surgery and Intensive Care Medicine, Dept. of

Anaesthesiology and Intensive Care Medicine, Medical

University of Graz, Graz, Austria

S. Heschl, MD PhD

stefan.heschl@medunigraz.at

M. Schörghuber, MD

michael.schoerghuber@medunigraz.at
}

\author{
P. Srekl-Filzmaier, MD $\cdot$ V. Weixler, MD \\ Div. of Cardiac Surgery, Dept. of Surgery, Medical University \\ of Graz, Graz, Austria \\ P. Srekl-Filzmaier, MD \\ petra.filzmaier@medunigraz.at \\ V. Weixler, MD \\ viktoria.weixler@gmx.com \\ T. Stojakovic, MD · S. Zelzer, MSc \\ Clinical Institute of Medical and Chemical Laboratory \\ Diagnostics, University Medical Centre Graz, Graz, Austria \\ T. Stojakovic, MD \\ stojakovic@gmx.at \\ S. Zelzer, MSc \\ sieglinde.zelzer@medunigraz.at \\ K. Amrein, MD \\ Div. of Endocrinology and Diabetology, Dept. of Internal \\ Medicine, Medical University of Graz, Graz, Austria \\ karin.amrein@medunigraz.at
}


Conclusion The 25(OH)D measurements by chemiluminescence assays can noticeably deviate from those measured by LC-MS/MS, which can be considered the unequivocal gold standard. These assays may still be acceptably reliable in the screening for vitamin $\mathrm{D}$ deficiency, especially in the setting of low vitamin D levels. Stricter definitions, e.g. serum 25(OH)D levels lower than $12 \mathrm{ng} / \mathrm{ml}$, may be used to diagnose deficiency with low false positive rate.

Trial Registration DRKS00009216, German Clinical Trials Registry (www.drks.de)

Keywords Vitamin D · Vitamin D deficiency · Critical care $\cdot$ Diagnosis

$\begin{array}{ll}\text { Abbreviations } \\ \text { 1,25(OH })_{2} \mathrm{D} & \text { 1,25-Dihydroxyvitamin D } \\ 25(\mathrm{OH}) \mathrm{D} & \text { 25-Hydroxyvitamin D } \\ \text { AVR } & \text { Aortic valve replacement } \\ \text { BMI } & \text { Body mass index } \\ \text { CABG } & \text { Coronary artery bypass grafting } \\ \text { ECLIA } & \text { Electrochemiluminescence assay } \\ \text { IQR } & \text { Interquartile range } \\ \text { LC-MS/MS } & \text { Liquid chromatography-mass spectro- } \\ & \text { scopy/mass spectrometry } \\ \text { VDBP } & \text { Vitamin D binding protein }\end{array}$

\section{Introduction}

Low vitamin D status was reported to be significantly associated with a poor outcome in critically ill patients in several studies over the last decade [1-3]. These findings led to the performance of one large randomized clinical trial of high-dose vitamin D supplementation, albeit an overall negative trial, which sparked further scientific and clinical interest because a mortality benefit was found in a prespecified subgroup of patients deemed to be severely vitamin D deficient [4].

Since poor vitamin D status may contribute to excess mortality in critical illnesses, vitamin D treatment seems to be feasible, safe and possibly advantageous. As vitamin $\mathrm{D}$ deficiency is also highly prevalent in this setting, high-dose vitamin $D$ treatment [5] may become an adjunctive therapy in critical care in the future; however, patient selection is important and some data suggest that the definition of deficiency may be different in this patient population [6].

Some studies in both critically ill and non-critically ill patients have raised the possibility that vitamin D status is inversely associated with inflammation and that levels may decrease rapidly during acute inflammation as well as fluid loading $[7,8]$. Low vitamin D levels have been suggested to be reflective of the severity of illness in critically ill patients rather than being an independent influencing factor on outcome $[9,10]$. The use of 25-hydroxyvitamin D [25(OH)D] may be unreliable in critical illness, since both $25(\mathrm{OH}) \mathrm{D}$ and serum vitamin $\mathrm{D}$ binding protein (VDBP) have been shown to significantly de- crease during inflammation [8, 9]. Additionally, there is ongoing debate about which vitamin $\mathrm{D}$ metabolite is best suited to represent the vitamin $\mathrm{D}$ status in critically ill patients and which methods should be employed [11]. Measurement of serum 25(OH)D by LC-MS/MS has been found to be superior to the use of immunoassays in non-critically ill patients who received a fluid bolus of crystalloid solution [12].

When turnaround times should be minimal the use of automated readily available methods of $25(\mathrm{OH}) \mathrm{D}$ testing is certainly preferable to the time-consuming method of LC-MS/MS in clinical routine [13, 14]. International standardization of current $25(\mathrm{OH}) \mathrm{D}$ immunoassays has reduced previously reported interlaboratory variation $[15,16]$; however, differences seem to be more prominent in specific populations, such as hemodialysis patients, critically ill individuals or pregnant women [17, 18]. Regular LC-MS methods may also detect the biologically inactive C3-epimer which may significantly contribute to $25(\mathrm{OH}) \mathrm{D}$ concentrations and can therefore lead to overestimation of $25(\mathrm{OH}) \mathrm{D}$ levels $[19,20]$. The percentage of this inactive epimer seems to be higher than reported in other populations but its role in critical care is currently unknown.

\section{Patients, materials and methods}

\section{Aim, design and setting}

A prospective observational pilot study was performed in adult patients undergoing major cardiovascular surgery by analyzing vitamin $\mathrm{D}$ levels at different time points preoperatively and postoperatively using a widely available, rapid and inexpensive assay (ECLIA, chemiluminescence technology, IDS-iSYS, Immunodiagnostic Systems Holdings, Tyne \& Wear, United Kingdom) and the gold standard LC-MS/MS (including detection of the C3 epimer) to confirm and quantify the decrease in vitamin D levels. The study aimed to evaluate the agreement between these methods in the diagnosis of vitamin $\mathrm{D}$ deficiency according to commonly used thresholds, to quantify the inactive C3 epimer and its contribution to total $25(\mathrm{OH}) \mathrm{D}$ levels, assess the impact of fluid loading and inflammation on vitamin $\mathrm{D}$ status and on the utility of the measurement methods in the diagnosis of vitamin D deficiency.

\section{Study population and inclusion criteria}

Adult patients scheduled for cardiovascular surgical procedures requiring cardiopulmonary bypass (CPB, e.g. coronary artery bypass grafting, $\mathrm{CABG}, \mathrm{CABG}$ plus valve surgery, double valve surgery, thoracic aortic aneurysm repair) who were deemed to have a high risk of prolonged postoperative intensive care unit (ICU) stay ( $48 \mathrm{~h}$ or longer) were included in this study. Patients undergoing elective and acute procedures were 
included if patients were able to give informed consent preoperatively. Patients undergoing mitral valve surgery were not included to avoid parallel inclusion in a competing trial.

\section{Sample collection and laboratory analysis}

Blood samples were drawn as part of routine clinical interventions at predefined time points during the course of preoperative evaluation, the surgical procedure and the ICU stay. These timepoints were: preoperative baseline ( $\mathrm{t} 1)$, after weaning from CPB ( $\mathrm{t} 2)$, on admission to ICU (t3) and the mornings of the first $(\mathrm{t} 4)$ and second $(\mathrm{t} 5)$ postoperative days.

The $25(\mathrm{OH}) \mathrm{D}$ levels and $1,25(\mathrm{OH})_{2} \mathrm{D}$ levels were measured using an assay based on chemiluminescence technology (IDS-iSYS, Immunodiagnostic Systems). For $25(\mathrm{OH}) \mathrm{D}$, the assay coefficients of variation for control levels are $13.4 \%$ at $13 \mathrm{ng} / \mathrm{mL}, 10 \%$ at $31 \mathrm{ng} / \mathrm{mL}$, and $9.4 \%$ at $64 \mathrm{ng} / \mathrm{ml}$. The lower detection limit of this test is $7.0 \mathrm{ng} / \mathrm{ml}$; values below the lower detection limit were used as $3.5 \mathrm{ng} / \mathrm{ml}$ for this analysis according to convention. The performing laboratory routinely participates in the vitamin D external quality assessment scheme (DEQAS) program [16]. Routine laboratory parameters as well as parameters concerning the vitamin $\mathrm{D}$ axis and markers of bone metabolism were analyzed using fresh serum samples. Liquid chromatography tandem mass spectrometry (LC-MS/MS) using commercially available, standardized columns and sera (ClinMass ${ }^{\circledR}$ complete kit for vitamin D analysis, Recipe ${ }^{\circledR}$, Munich, Germany) was used to analyze frozen samples $\left(-70^{\circ} \mathrm{C}\right)$ in a batch following completion of patient inclusion.

\section{Statistical analysis}

Demographic data and indicators of physical status, relevant routine laboratory results and parameters of intervention of the study population are presented as median values \pm interquartile ranges (IQR). Changes from baseline vitamin $D$ status over the investigation period were tested using Wilcoxon rank-sum test. Relative changes in vitamin D levels over time were assessed for linear correlation with fluid balance using Pearson's correlation coefficient. The concurrence of the investigated methods of vitamin D measurements (ECLIA immunoassay, LC-MS/MS) was examined using mean difference, Pearson's correlation coefficient, and Bland-Altman analysis. The diagnostic utility of measurements using both methods following fluid loading and inflammation was assessed by comparison with baseline LC-MS/MS measurements as the gold standard. Generally agreed upon cut-off values for the overall population [21] as well as a potential cut-off value in critical illness derived from a previous study [4] were evaluated. All statistical analyses were performed using SPSS 25 (IBM SPSS Statistics, 2018,
Table 1 Baseline and outcome characteristics of patients providing samples for the study $(n=26)$

\begin{tabular}{l|l}
\hline Variable & 26 \\
\hline$n$ of patients & $67(60-76)$ \\
\hline Age (years) (median, IQR) & $19(73 \%)$ \\
\hline Male sex (n, \%) & $26(100 \%)$ \\
\hline Caucasian ethnicity (n, \%) & $26(24-28)$ \\
\hline BMI (median, IQR) & $4(3-4)$ \\
\hline ASA score (median, IQR) & \\
\hline Pre-existing conditions and treatments (n, \%) & $8(31 \%)$ \\
\hline Chronic kidney disease & $0(0 \%)$ \\
\hline Chronic hepatic disease & $1(4 \%)$ \\
\hline Osteoporosis & $2(8 \%)$ \\
\hline Vitamin D treatment & \\
\hline Type of surgery (n, \%) & $12(46 \%)$ \\
\hline CABG & $4(15 \%)$ \\
\hline AVR & $5(19 \%)$ \\
\hline CABG + AVR & $1(4 \%)$ \\
\hline AVR + atrial septal defect repair & $4(15 \%)$ \\
\hline Aortic aneurysm repair + AVR & \\
\hline Length of stay (days) (median, IQR) & $3(2-5)$ \\
\hline ICU & $14(13-15)$ \\
\hline Hospital & $0(0 \%)$ \\
\hline Hospital mortality ( $n$, \%) & \\
\hline $\begin{array}{l}\text { ASA score American Society of Anesthesiologists physical status clas- } \\
\text { sification system, AVR aortic valve replacement, BMI body mass index, } \\
\text { CABG coronary artery bypass grafting, ICU intensive care unit, IQR in- } \\
\text { terquartile range }\end{array}$ & \\
\hline
\end{tabular}

Armonk, NY, USA) and $p$ values below 0.05 were considered significant.

\section{Results}

A total of 26 patients providing 130 samples for analysis were included in this analysis. These patients were predominately male $(n=19,73 \%)$, all of Caucasian ethnicity, with a median age of 67 years (range 60-76 years). Patients were treated in the ICU for a median of 3 days (2-6 days) and remained hospitalized for a median of 14 days (13-17 days). Both in the ICU and in the hospital there were no fatalities $(n=0,0 \%)$ in this cohort (Table 1).

Patients were treated according to local protocol based on clinical needs as assessed by the treating physicians. Parameters of physical status, relevant routine laboratory measurements and fluid balance are shown in Table 2.

\section{Vitamin $D$ trends}

The median 25(OH)D level at baseline (t1) measured by the chemiluminescence assay was $21.7 \mathrm{ng} / \mathrm{ml}$ (13.8-26.0 ng/ml), which dropped to $18.4 \mathrm{ng} / \mathrm{ml}(14.2-$ $23.1 \mathrm{ng} / \mathrm{ml}, p=0.15$ for comparison with $\mathrm{t} 1$ ) over the course of cardiopulmonary bypass (t2). On ICU admission (t3) median 25(OH)D level was $18.9 \mathrm{ng} / \mathrm{ml}$ 
Table 2 Fluid balance, markers of inflammation and measures of the vitamin D axis at the five observation time points of the study (t1-t5); depicted are median (IQR)

\begin{tabular}{|c|c|c|c|c|c|}
\hline & $\mathrm{t} 1$ & $\mathrm{t} 2$ & t3 & t4 & t5 \\
\hline Fluid balance (ml) & - & $3700(3100-4111)$ & $920(-535-1378)$ & $1895(1265-3038)$ & $124(-201-825)$ \\
\hline Hematocrit (\%) & $35.5(31.0-38.4)$ & $26.2(25.1-28.7)$ & $31.0(26.0-34.4)$ & $29.5(25.6-32.9)$ & $27.8(24.8-30.4)$ \\
\hline Leukocytes (G/l) & $4.8(4.2-5.8)$ & $7.2(6.0-10.4)$ & $9.7(6.4-12.1)$ & $10.3(8.2-12.2)$ & $11.7(9.7-12.7)$ \\
\hline $\mathrm{CRP}(\mathrm{mg} / \mathrm{l})$ & $1.3(0.7-2.3)$ & $1.1(0.6-2.0)$ & $2.0(0.7-4.6)$ & $63.4(50.4-77.6)$ & $146.0(92.4-203.5)$ \\
\hline Albumin (g/dl) & $3.5(3.3-3.7)$ & $2.4(2.2-2.7)$ & $2.8(2.4-3.0)$ & $3.0(2.8-3.3)$ & $2.9(2.6-3.1)$ \\
\hline Total protein (g/dl) & $6.0(5.7-6.3)$ & $4.3(3.7-4.6)$ & $4.7(4.2-5.0)$ & $5.1(4.6-5.5)$ & $5.2(4.9-5.7)$ \\
\hline PTH (pg/ml) & $48.2(30.6-60.1)$ & $29.1(21.2-44.0)$ & $39.8(23.3-55.7)$ & $44.6(28.0-70.2)$ & $51.1(33.8-73.5)$ \\
\hline $\mathrm{Ca}^{2+}$, total $(\mathrm{mmol} / \mathrm{l})$ & $2.29(2.20-2.34)$ & $2.11(2.06-2.20)$ & $2.20(2.08-2.25)$ & $2.12(2.03-2.23)$ & $2.08(2.00-2.14)$ \\
\hline $\mathrm{Ca}^{2+}$, ionized (mmol/l) & $1.18(1.15-1.20)$ & $1.19(1.17-1.23)$ & $1.18(1.16-1.27)$ & $1.11(1.06-1.15)$ & $1.10(1.05-1.14)$ \\
\hline $1,25(\mathrm{OH})_{2} \mathrm{D}(\mathrm{pmol} / \mathrm{l})$ & $76(36-89)$ & $34(21-51)$ & $35(19-54)$ & $34(23-64)$ & $29(18-64)$ \\
\hline
\end{tabular}

(10.3-23.7 $\mathrm{ng} / \mathrm{ml})$, still lower than at baseline $(p=0.09)$. On the first postoperative day (t4), median $25(\mathrm{OH}) \mathrm{D}$ level was $21.2 \mathrm{ng} / \mathrm{ml}(11.6-26.3 \mathrm{ng} / \mathrm{ml} p=0.29)$. On the second postoperative day (t5), median level was at $17.6 \mathrm{ng} / \mathrm{ml}$ (13.8-22.0 ng/ml, $p=0.16$ ) (Fig. 1).

When measured by mass spectrometry the median $25(\mathrm{OH}) \mathrm{D}$ at $\mathrm{t} 1$ was $19.8 \mathrm{ng} / \mathrm{ml}(12.1-25.0 \mathrm{ng} / \mathrm{ml})$. There was a marked drop following fluid loading by $\mathrm{CPB}$ until t2 $(12.5 \mathrm{ng} / \mathrm{ml}, 7.5-16.3 \mathrm{ng} / \mathrm{ml}, p=0.001)$. Measurements following ICU admission and intensive care treatment were $12.1 \mathrm{ng} / \mathrm{ml}(8.8-15.1 \mathrm{ng} / \mathrm{ml}, p<0.001)$ at $\mathrm{t} 3,12.9 \mathrm{ng} / \mathrm{ml}(7.2-18.1 \mathrm{ng} / \mathrm{ml}, p=0.004)$ at $\mathrm{t} 4$ and $15.1 \mathrm{ng} / \mathrm{ml}(8.5-17.6 \mathrm{ng} / \mathrm{ml}, p<0.001)$ at t5 (Fig. 1).

\section{Effect of fluid loading}

Fluid loading during CPB for surgery and maintenance of homeostasis during intensive care led to noticeable changes in $25(\mathrm{OH}) \mathrm{D}$ levels. There was, however, considerable variation in both the magnitude of these changes and their detection by

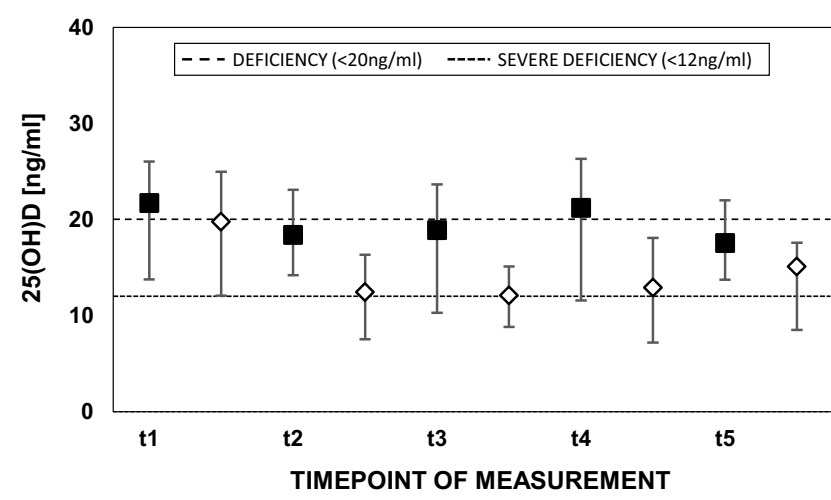

Fig. 1 Median (interquartile range) 25(OH)D measurements by ECLIA (black squares) and LC-MS/MS (white diamonds) at preoperative baseline ( $\mathrm{t} 1$ ), after the end of cardiopulmonary bypass (t2), on admission to ICU (t3), and on the first (t4) and second (t5) postoperative day. 25(OH)D 25-hydroxyvitamin D, ECLIA electrochemiluminescence assay, LC-MS/MS liquid chromatography-mass spectroscopy/mass spectrometry the investigated measurement methods. Using LCMS/MS, median relative changes in $25(\mathrm{OH}) \mathrm{D}$ levels were $-22.6 \%(-54.5 \%$ to $-19.5 \%)$ between $\mathrm{t} 1$ and $\mathrm{t} 2$, $+1.5 \%(-27.3 \%$ to $18.2 \%)$ between $\mathrm{t} 2$ and $\mathrm{t} 3,+15.2 \%$ $(-3.3 \%$ to $32.9 \%)$ between $\mathrm{t} 3$ and $\mathrm{t} 4$ and $+7.8 \%(-5.3 \%$ to $27.3 \%$ ) between $\mathrm{t} 4$ and $\mathrm{t} 5$. In comparison, using the chemiluminescence assay, relative changes were $\pm 0.0 \%(-28.6 \%$ to $+7.9 \%)$ between $\mathrm{tl}$ and $\mathrm{t} 2,+12.4 \%$ $(-12.8 \%$ to $+25.3 \%)$ between $\mathrm{t} 2$ and $\mathrm{t} 3,+17.2 \%(-0.1 \%$ to $+29.7 \%)$ between $\mathrm{t} 3$ and $\mathrm{t} 4$, and $-0.7 \%(-39.2 \%$ to $+9.4 \%$ ) between $t 4$ and $t 5$. Due to this variation, no linear correlation between relative $25(\mathrm{OH}) \mathrm{D}$ levels and fluid balance could be found for measurements by ECLIA; Pearson's correlation coefficient was -0.019 $(p=0.87)$. There was a weakly significant correlation between LC-MS/MS measurements and fluid balance; Pearson's $\mathrm{r}$ was $-0.28(p=0.03)$. Correlation between fluid balance and $25(\mathrm{OH}) \mathrm{D}$ was similarly poor at individual timepoints; Pearson's $r$ for ECLIA and fluid balance were: $0.00(p=0.99)$ at $\mathrm{t} 2,0.29(p=0.14)$ at $\mathrm{t} 3,-0.16(p=0.49)$ at $\mathrm{t} 4$ and $0.22(p=0.36)$ at $\mathrm{t} 5$; Pearson's $\mathrm{r}$ for LC-MS/MS and fluid balance were: -0.42 $(p=0.14)$ at t2, $0.01(p=0.97)$ at $\mathrm{t} 3,-0.32(p=0.24)$ at $\mathrm{t} 4$ and $0.13(p=0.62)$ at $\mathrm{t} 5$.

Hemodilution due to fluid loading had noticeable influences on other parameters of the vitamin $\mathrm{D}$ axis as well. Median (IQR) $1,25(\mathrm{OH})_{2} \mathrm{D}$ levels were $76 \mathrm{pmol} / \mathrm{l}(36-89 \mathrm{pmol} / \mathrm{l})$ at $\mathrm{tl}$ and dropped to $34 \mathrm{pmol} / \mathrm{l}(21-51 \mathrm{pmol} / \mathrm{l})$ at $\mathrm{t} 2$. No return to baseline was observed during the study duration; further median (IQR) $1,25(\mathrm{OH}) 2 \mathrm{D}$ levels were $35 \mathrm{pmol} / 1$ (19-54 pmol/l) at t3, $34 \mathrm{pmol} / \mathrm{l}$ (23-64 pmol/l) at t4 and $29 \mathrm{pmol} / \mathrm{l}(18-64 \mathrm{pmol} / \mathrm{l})$ at t5. Parathyroid hormone (PTH) was also affected by fluid loading; median PTH levels dropped from $48.2 \mathrm{pg} / \mathrm{ml}(30.6-60.1 \mathrm{pg} / \mathrm{ml})$ at $\mathrm{tl}$ to $29.1 \mathrm{pg} / \mathrm{mol}(21.2-44.0 \mathrm{pg} / \mathrm{mol})$ at $\mathrm{t} 2$. No compensatory overshoot was found; further median PTH levels were $39.8 \mathrm{pg} / \mathrm{ml}(23.3-55.7 \mathrm{pg} / \mathrm{ml})$ at $\mathrm{t} 3,44.6 \mathrm{pg} / \mathrm{ml}$ $(28.0-70.2 \mathrm{pg} / \mathrm{ml})$ at $\mathrm{t} 4$ and $51.1(33.8-73.5 \mathrm{pg} / \mathrm{ml})$ at t5. 
Fig. 2 Bland-Altman plot for $25(\mathrm{OH}) \mathrm{D}$ measurements by ECLIA and LC-MS/MS. Mean difference $=4.8 \mathrm{ng} / \mathrm{ml}$ $(\mathrm{SD} \pm 5.7 \mathrm{ng} / \mathrm{ml})$. 25(OH)D 25-hydroxyvitamin D, ECLIA electrochemiluminescence assay, LC-MS/MS liquid chromatography-mass spectroscopy/mass spectrometry, $S D$ standard deviation

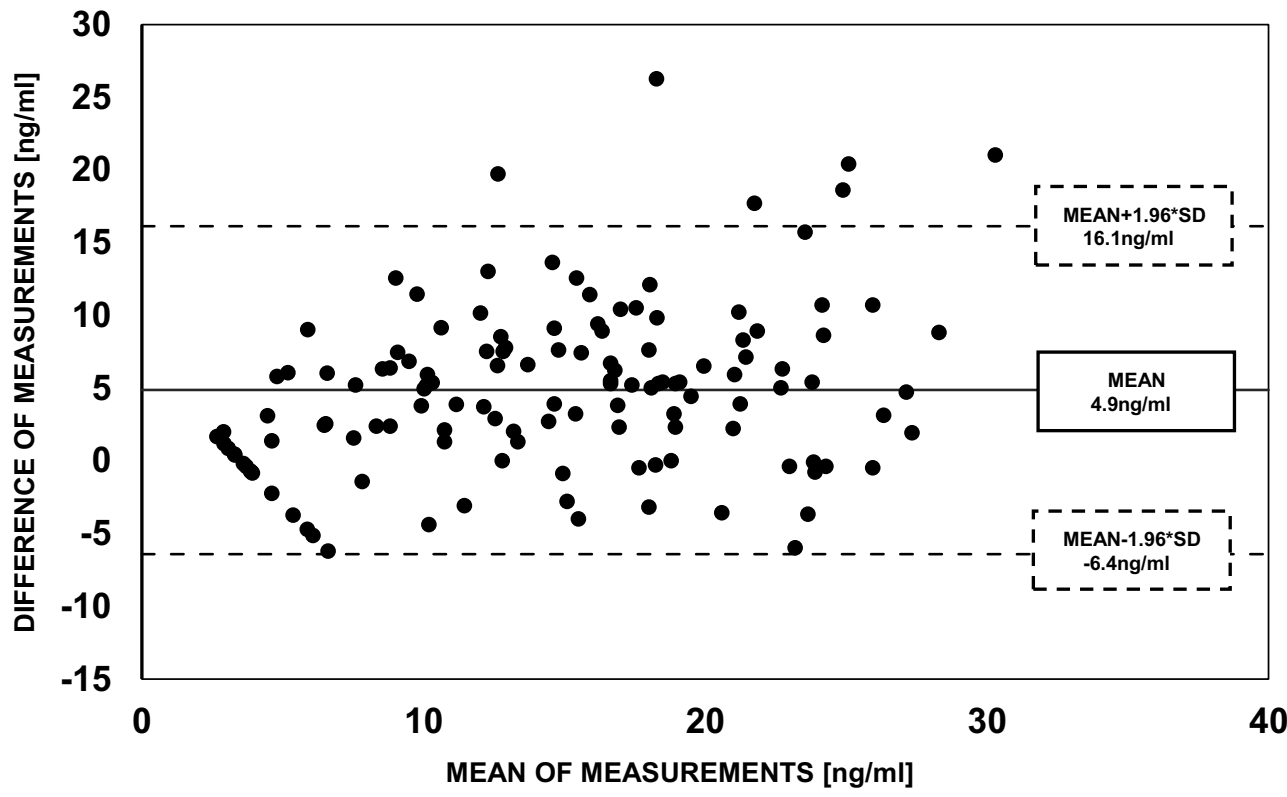

Table 3 Diagnostic characteristics of different 25(OH)D cut-off values and measurement methods in intraoperative and postoperative samples $(n=104)$ compared to their respective baselines; gold standard: preoperative vitamin $D$ deficiency $[25(\mathrm{OH}) \mathrm{D}<20 \mathrm{ng} / \mathrm{ml}]$ measured by LC-MS/MS

\begin{tabular}{|c|c|c|c|c|}
\hline & Sensitivity (\%) & Specificity (\%) & $\begin{array}{l}\text { PPV } \\
(\%)\end{array}$ & $\begin{array}{l}\text { NPV } \\
(\%)\end{array}$ \\
\hline \multicolumn{5}{|l|}{ ECLIA } \\
\hline $25(\mathrm{OH}) \mathrm{D}<20 \mathrm{ng} / \mathrm{ml}$ & 73 & 63 & 76 & 60 \\
\hline $25(\mathrm{OH}) \mathrm{D}<12 \mathrm{ng} / \mathrm{ml}$ & 38 & 98 & 96 & 49 \\
\hline \multicolumn{5}{|l|}{ LC-MS/MS } \\
\hline $25(\mathrm{OH}) \mathrm{D}<20 \mathrm{ng} / \mathrm{ml}$ & 98 & 13 & 64 & 83 \\
\hline $25(\mathrm{OH}) \mathrm{D}<12 \mathrm{ng} / \mathrm{ml}$ & 72 & 85 & 89 & 65 \\
\hline
\end{tabular}

\section{Discussion}

In this study it was demonstrated that changes during the perioperative phase and critical illness significantly altered both the findings of a commonly used chemiluminescence assay for vitamin $\mathrm{D}$ measurements and mass spectrometry. Acute fluid loading by CPB leads to a reduction in $25(\mathrm{OH}) \mathrm{D}$ levels of about one fifth of baseline values on an individual patient level. This is somewhat lower than in a previous small study in patients undergoing major cardiac surgery [7] and other studies in non-critically ill patients [8], which suggested a reduction up to $40 \%$ of baseline levels. While this reduction in serum $25(\mathrm{OH}) \mathrm{D}$ levels is physiologically plausible following a single significant volume expansion (median 3.7l, IQR 3.1-4.11) by CPB, interindividual variation in response was surprisingly high. Inference of premorbid vitamin D status from values measured later on therefore seems improper, especially in critically ill patients, whose volume status may be influenced by far more sources than one 
fluid bolus alone. This is confirmed by limited linear correlations between fluid balance as well as markers of inflammation and relative changes in $25(\mathrm{OH}) \mathrm{D}$ levels in this study. These alterations in vitamin D status in states of critical illness may contribute to overdiagnosis and potentially overtreatment later on. While supplementation of cholecalciferol during intensive care can be considered standard of care using doses recommended for the overall population (600-4000 IU daily), high bolus doses have been shown to be necessary in critical illness if correction of vitamin $\mathrm{D}$ deficiency is the goal [22]. In the only large randomized clinical trial investigating this intervention published to date, no significant benefit was found regarding the primary endpoint (length of stay) or overall mortality [4]. There was, however, a statistically significant and clinically potentially highly relevant reduction in mortality in severe vitamin D deficiency $(n=200 / 42 \%$ of the total population, $25(\mathrm{OH}) \mathrm{D}$ levels $<12 \mathrm{ng} / \mathrm{ml})$.

More specific patient selection is a possible explanation for this subgroup finding. Selecting patients that benefit most from interventions both in clinical trials and routine practise is considered ever more important in times of "precision medicine" $[6,23]$. This alternative cut-off for diagnosis of vitamin $\mathrm{D}$ deficiency was therefore tested in critically ill patients after fluid loading in this study. As could be expected from a narrower definition of the condition in question, the lower cut-off was indeed more specific for the diagnosis of vitamin $\mathrm{D}$ deficiency when preoperative $25(\mathrm{OH}) \mathrm{D}$ levels lower than $20 \mathrm{ng} / \mathrm{ml}$ measured by LC-MS/MS were used as the gold standard for comparison. Conversely, the rate of false negative findings would also be higher.

Readily available, economically reasonable and sufficiently specific tests are preferable both in everyday clinical practice and for conducting clinical trials to maximize the potential benefit of an intervention yet to be proven, such as high-dose vitamin D supplementation in critically ill patients. The reliability of a commercially available chemiluminescence assay (ECLIA) compared to mass spectrometry, the gold standard in this field was therefore assessed. Although the detection of the biologically inactive C3 epimer was claimed to lead to overestimation of vitamin D levels by LC-MS/MS, the findings refute this notion as no epimers were detected by LC-MS/MS, further corroborating its standing as the gold standard method.

\section{Strengths and limitations}

This study is obviously limited by the sample size. Recruitment of a larger patient cohort was not possible for logistic reasons. Furthermore, fluid loading by CPB for cardiac surgery is not necessarily the same as fluid loading for purposes such as hemodynamic resuscitation for sepsis in intensive care. The findings presented in this study do, however, add knowledge relevant both for everyday clinical practice and scien- tific purposes that may be used as the basis for the definition of vitamin $\mathrm{D}$ deficiency as a treatment and study target.

\section{Conclusion}

Diagnosis of vitamin D deficiency in the status of fluid loading and inflammation, such as the perioperative period and critical illness, can be complicated by hemodilution. Inference of baseline values from downstream measurements is not reliably possible. Stricter definitions, such as serum $25(\mathrm{OH}) \mathrm{D}$ levels lower than $12 \mathrm{ng} / \mathrm{ml}$ may therefore be used to diagnose vitamin $\mathrm{D}$ deficiency with a low false positive rate. Measurements by commonly available chemiluminescence assays may deviate noticeably from the mass spectrometry gold standard; however, they are acceptably reliable in the acute setting when vitamin D deficiency has to be diagnosed.

Acknowledgements We would like to acknowledge the contributions and support provided for this study by (in alphabetical order) Andrea Amegah-Sakotnik, Sonja Fruhwald, Markus Herrmann, Andreas Meinitzer, Cornelia Missbrenner, Barbara Obermayer-Pietsch, Wolfgang Toller and all patients and nursing personnel involved in this study. We thank the Institut Aguettant and the Medical University of Graz for the funding they provided for this study.

Funding This work was supported by Institut Aguettant [Institut Aguettant Research Prize] and funds of the Medical University of Graz.

Funding Open access funding provided by Medical University of Graz.

\section{Compliance with ethical guidelines}

Conflict of interest P. Zajic, S. Heschl, M. Schörghuber, P. Srekl-Filzmaier, T. Stojakovic, V. Weixler, and S. Zelzer declare that they have no competing interests. K. Amrein reports speaker fees from Fresenius Kabi.

Ethical standards All procedures performed in studies involving human participants were in accordance with the ethical standards of the institutional and/or national research committee and with the 1975 Helsinki declaration and its later amendments or comparable ethical standards. Informed consent was obtained from all individual participants included in the study. The institutional review board (Medical University of Graz, IRB00002556) approved of this study.

Open Access This article is distributed under the terms of the Creative Commons Attribution 4.0 International License (http://creativecommons.org/licenses/by/4.0/), which permits unrestricted use, distribution, and reproduction in any medium, provided you give appropriate credit to the original author(s) and the source, provide a link to the Creative Commons license, and indicate if changes were made. 


\section{References}

1. Braun AB, a LA, Moromizato T, Gibbons FK, Giovannucci E, Christopher KB. Association of low serum 25-hydroxyvitamin D levels and acute kidney injury in the critically ill. Crit Care Med. 2012;40:3170-9. https://doi.org/10.1097/CCM. 0b013e318260c928.

2. Moromizato T, Litonjua A, Braun AB, Gibbons FK, Giovannucci E, Christopher KB. Association of low serum 25-hydroxyvitamin D levels and sepsis in the critically ill. Crit Care Med. 2013; https://doi.org/10.1097/CCM. 0b013e31829eb7af.

3. Amrein K, Zajic P, Schnedl C, Waltensdorfer A, Fruhwald S, Holl A, et al. Vitamin D status and its association with season, hospital and sepsis mortality in critical illness. Crit Care. 2014;18:R47. https://doi.org/10.1186/cc13790.

4. Amrein K, Schnedl C, Holl A, Riedl R, Christopher KB, Pachler C, et al. Effect of high-dose vitamin D 3 on hospitallength of stay in critically ill patients with vitamin D deficiency. JAMA. 2014;312:1520. https://doi.org/10.1001/ jama.2014.13204.

5. Amrein K, Sourij H, Wagner G, Holl A, Pieber TR, Smolle KH, et al. Short-term effects of high-dose oral vitamin D3 in critically ill vitamin D deficient patients: a randomized, double-blind, placebo-controlled pilot study. Crit Care. 2011;15:R104. https://doi.org/10.1186/cc10120.

6. Martucci G, McNally D, Parekh D, Zajic P, Tuzzolino F, Arcadipane A, et al. Trying to identify who may benefit most from future vitamin D intervention trials: a post hoc analysis from the VITDAL-ICU study excluding the early deaths. Crit Care. 2019;23:200. https://doi.org/10.1186/ s13054-019-2472-z.

7. Krishnan A, Ochola J, MundyJ, Jones M, Kruger P, Duncan E, et al. Acute fluid shifts influence the assessment of serum vitamin D status in critically ill patients. Crit Care. 2010; https://doi.org/10.1186/cc9341.

8. Waldron JL, Ashby HL, Cornes MP, Bechervaise J, Razavi C, Thomas OL, et al. Vitamin D: a negative acute phase reactant. J Clin Pathol. 2013;66:620-2. https://doi.org/10. 1136/jclinpath-2012-201301.

9. Krishnan A, Venkatesh B. Vitamin D measurement in the intensive care unit: methodology, clinical relevance and interpretation of a random value. Inflamm Allergy Drug Targets. 2013;12:230-8.

10. Ghashut R, Talwar D, Kinsella J, Duncan A, McMillan DC. The effect of the systemicinflammatory response on plasma vitamin $25(\mathrm{OH}) \mathrm{D}$ concentrations adjusted for albumin. Plos One. 2014;9:e92614. https://doi.org/10.1371/journal. pone.0092614.

11. Quraishi S, Bittner E, Blum L, McCarthy CM, Bhan I, Camargo C. Prospective study of vitamin d status at initiation of care in critically ill surgical patients and risk of 90-day mortality. Crit Care Med. 2014;42:1365-71.https://doi.org/ 10.1097/CCM.0000000000000210.
12. Rousseau AF, Damas P, Janssens M, Kalin S, Ledoux D, Le Goff $\mathrm{C}$, et al. Critical care and vitamin D status assessment: What about immunoassays and calculated free 25OH-D? Clin Chim Acta. 2014;437:43-7. https://doi.org/10.1016/j.cca.2014.07.007.

13. Heureux N. Vitamin D testing - where are we and what is on the horizon? Adv Clin Chem. 2017;78:59-101. https://doi. org/10.1016/bs.acc.2016.07.002.

14. Garg U. 25-Hydroxyvitamin D testing. Clin Lab Med. 2018;38:439-53. https://doi.org/10.1016/j.cll.2018.05.007.

15. Schöttker B, Jansen EHJM, Haug U, Schomburg L, Köhrle J, Brenner H. Standardization of misleading Immunoassay based 25-hydroxyvitamin D levels with liquid chromatography tandem-mass spectrometry in a large cohort study. Plos One. 2012;7:e48774. https://doi.org/10.1371/journal. pone.0048774.

16. Carter GD, Berry J, Durazo-Arvizu R, Gunter E, Jones G, Jones J, et al. Hydroxyvitamin D assays: an historical perspective from DEQAS. J Steroid Biochem Mol Biol. 2018;177:30-5. https://doi.org/10.1016/j.jsbmb.2017.07. 018.

17. CavalierE,LukasP,CrineY,PeetersS, CarlisiA,LeGoffC, etal. Evaluation of automated immunoassays for $25(\mathrm{OH})$-vitaminD determinationin different critical populations before and after standardization of the assays. Clin Chim Acta. 2014;431:60-5. https://doi.org/10.1016/j.cca.2014.01.026.

18. Depreter B, Heijboer AC, Langlois MR. Accuracy of three automated 25-hydroxyvitamin D assays in hemodialysis patients. Clin Chim Acta. 2013;415:255-60. https://doi.org/10.1016/j.cca.2012.10.056.

19. Bailey D, Veljkovic K, Yazdanpanah M, Adeli K. Analytical measurement and clinical relevance of vitamin D3 C3epimer. Clin Biochem. 2013;46:190-6. https://doi.org/10. 1016/j.clinbiochem.2012.10.037.

20. Mydtskov ND, Lykkedegn S, Fruekilde PBN, Nielsen J, Barington T, Christesen HT. S-25-hydroxyvitamin D and C3epimers in pregnancy and infancy: an Odense Child Cohort study. Clin Biochem. 2017;50:988-96. https://doi.org/10. 1016/j.clinbiochem.2017.07.001.

21. Holick MF, Binkley NC, Bischoff-Ferrari HA, Gordon CM, Hanley DA, Heaney RP, et al. Evaluation , treatment, and prevention of vitamin D deficiency. J Clin Endocrinol Metab. 2011;96:1911-30.

22. Perron RM, Lee P. Efficacy of high-dose vitamin D supplementation in the critically ill patients. Inflamm Allergy Drug Targets. 2013;12:273-81.

23. Vincent J-L. The coming era of precision medicine for intensive care. Crit Care. 2017;21:314. https://doi.org/10. 1186/s13054-017-1910-z.

Publisher's Note Springer Nature remains neutral with regard to jurisdictional claims in published maps and institutional affiliations. 